\title{
Investigation of the effects of rapamycin on the mTOR pathway and apoptosis in metastatic and non-metastatic human breast cancer cell lines
}

\author{
Ekizceli $\mathrm{G}^{1^{*}}$, Uluer $\mathrm{ET}^{2 *}$, Inan $\mathrm{S}^{3}$ \\ Department of Histology and Embryology, Institute of Health Science, Bursa Uludag University, \\ Bursa, Turkey. ekizceli.g@gmail.com
}

\begin{abstract}
AIM: The aim of this study was to analyze the effects of rapamycin treatment on apoptosis via mTOR pathway in metastatic and non-metastatic human breast cancer cell lines by immunohistochemical and TUNEL analysis. METHOD: MCF-7 and MDA-MB 231 cell lines were incubated under standard conditions forming Rapamycin and control groups. In immunohistochemical evaluation; mTOR pathway was evaluated with anti-IGF1, antiPI3K, anti-pAKT1/2/3, anti-mTORC1, anti-mTORC2 and anti-ERK1 antibodies. The effect of apoptosis was also confirmed by TUNEL method.

RESULTS: In this study, activation of PI3K/AKT/mTOR and related molecular pathways in the MDA-MB 231 and MCF-7 breast cancer cell line was evaluated and it was observed that these pathways could play a key role in cancer development. Increased apoptotic cells were observed in MTORC1 inhibition by Rapamycin administration. CONCLUSION: Targeting the mTOR pathway in breast cancer treatment may be a treatment option. In addition, the demonstration and confirmation of increased apoptosis in Rapamycin treated groups suggested that Rapamycin, an inhibitor of mTOR, is promising in the treatment of breast cancer (Tab. 2, Fig. 3, Ref. 66). Text in PDF www.elis.sk.

KEY WORDS: MDA-MB 231, MCF-7, breast cancer, mTOR, rapamycin.
\end{abstract}

\section{Introduction}

Breast cancer is the most common type of cancer in women worldwide (1). In 2018, around 600,000 women lost their lives due to breast cancer in the world (2). Invasive breast cancers express in about $75 \%$ estrogen receptor (ER) and in about $30 \%$ human epidermal growth factor receptor 2 (HER2) (3-5). More than $90 \%$ of breast cancer-related deaths have been reported as complications caused by metastasis (6). Metastatic breast cancer lesions have been reported to develop in 30-60\% in the bone, $4-10 \%$ in the brain, $15-32 \%$ in the liver and $21-32 \%$ in the lungs (7). Molecular mechanisms that determine which organs will be colonized by breast cancer are complex. However, breast cancer can be divided into four major clinical subtypes depending on gene expression profiles, estrogen (ER), progesterone (PR) or human epidermal growth factor receptor 2 (HER2) receptor and proliferation status (8). For the treatment of breast cancer, investigation of molecular

${ }^{1}$ Department of Histology and Embryology, Institute of Health Science, Bursa Uludag University, Bursa, Turkey, ${ }^{2}$ Department of Histology and Embryology, School of Medicine, Manisa Celal Bayar University, Manisa, Turkey, and ${ }^{3}$ Department of Histology and Embryology, School of Medicine, Izmir Economy University, Izmir, Turkey

Address for correspondence: G. Ekizceli, Department of Histology and Embryology, Institute of Health Science, Bursa Uludag University, Bursa, Turkey

*The first two authors contributed equally. mechanisms which effect the cell proliferation and survival are now at the forefront. In recent years, research has shown PI3K/ AKT/mTOR and Ras/Raf/MEK/ERK pathways are frequently dysregulated in several cancers, including breast cancer $(9,10)$.

The PI3K phosphorylates phosphatidylinositol diphosphate (PIP2) to phosphatidylinositol triphosphate (PIP3) in order to promote the AKT activation (10). Akt activation leads to activation of mTORC1, which contributes to cell growth, proliferation and metabolism, but can also promote tumorigenesis (11-13). mTORC1 is activated by many metabolic molecular events such as growth factors, energy status, proinflammatory cytokines, oxygen levels, amino acids and canonical wingless type (Wnt) pathway. Growth factors such as insulin-like growth factor 1 (IGF1) which is one of the antibodies used in our study, receptor tyrosine kinases (RTKs) and PI3K/AKT pathway which is also subject to our study and Ras/ Raf/Mek/Erk signal pathway are effective on mTORC1 $(14,15)$. Activation of MTORCl directly phosphorylates effectors such as ribosomal S6K1, leading to increased protein synthesis and cell survival. In addition, S6K1 activation has been reported to be involved in mTORC2 activation (16) and inhibits PI3K signaling, which further attenuates Akt activation (17).

mTOR is a serine/threonine protein kinase of the phosphoinositide 3-kinase (PI3K)-related kinase family, which plays a role in regulating cell growth, aging and metabolism (18). mTOR generally comprises two complexes, functionally and structurally different, called mTOR complex 1 (mTORC1) and mTOR complex 
2 (mTORC2) (18). mTOR is targeted by rapamycin, but mTORC1 and $\mathrm{mTORC} 2$ have different susceptibilities to rapamycin. Essentially, mTORC1 is directly inhibited by a complex formed by rapamycin and FKBP12 protein (19). But studies show that rapamycin did not inhibit mTORC2 $(11,20,21)$. mTORC2 protein is thought to support cell viability by activating apoptotic protein BCL2 (B-Cell Lymphoma 2) by phosphorylating AKT and BAD proteins in the cytoplasm (22). The mTORC2 contains mTOR, but the most characteristic of this complex is that it phosphorylates the AKT protein (23). Interestingly, mTORC2 suppresses AKT signaling after stimulation by mTORC1 (24).

MAP kinases control cellular events for many complex shortterm changes, such as embryogenesis, cell differentiation, cell proliferation and cell death, which are essential for homeostasis and acute hormonal responses (25). The MAPK signaling pathway consists of RAF, MEK and ERK proteins, which are essential for proliferation in many cancer cells as well as in normal cells (26). ERK1 and ERK2 are two identical proteins with a weight of 43 and $41 \mathrm{kDa}$ and $83 \%$ similarity $(27,28)$. Varied amounts of ERK1 and ERK2 were detected in almost all tissues, including differentiated tissues (25).

Purification of mTOR and the discovery of rapamycin as a physical target accelerated the studies in this field (29-31). mTOR inhibitors were originally developed as immunosuppressants, but have been approved for use in other cancers including renal cell carcinoma, neuroendocrine tumors of the pancreas, and subependymal giant cell astrocytomas as studies progress and new inhibitors emerge (32). The anti-cancer activity of rapamycin has been shown in several studies $(33,34)$.

In this study, we aimed to evaluate the effects of Rapamycin, which is an inhibitor of mTORC1, on the metastatic MDA-MB 231 and non-metastatic MCF-7 breast cancer cell lines with primary antibodies involved in PI3K, MAPK and apoptotic signal pathways using indirect immunohistochemistry and TUNEL methods.

\section{Materials and methods}

\section{Cell culture and cell therapy}

Metastatic (MDA-MB 231, 92020424, ECACC, Salisbury, UK) and non-metastatic (MCF-7, ACC115, DSMZ, Braunschweig, Germany) breast cancer cell lines were cultured in RPMI1640 (F1213, Biochrom AG, Berlin, Germany) medium containing $10 \%$ fetal bovine serum (FBS, S0113, Biochrom), $1 \%$ L-glutamine (K0283, Biochrom) and $1 \%$ Penicillin/Streptomycin (A2213, Biochrom). The cells were maintained at $37{ }^{\circ} \mathrm{C}$ in $5 \%$ $\mathrm{CO}_{2}$. Sterilized $12 \mathrm{~mm}$ diameter circular cover glasses $(0.11152$ million, Marienfeld Lab., Königshofen, Germany), were placed in 24-well plates. $500 \mu \mathrm{l} \mathrm{FBS}$ was added to each well of the plate for $30 \mathrm{~min}$ at room temperature. After aspiration of the FBS from the cells were plated in flasks and allowed to grow under routine conditions until about $70 \%$ confluent. After growing the cells on 24 well-plate, the $\mathrm{IC}_{50}$ dose of Rapamycin (Rapamune, Sirolimus, Pfizer, Kent, UK) was determined as $1 \mu \mathrm{g} / \mathrm{ml}$.

The experimental design was determined as the MDA-MB 231-control group (MDA-MB 231 metastatic breast cancer cells without exposure to any drug), MCF-7-control group (MCF-7 non-metastatic breast cancer cells without exposure to any drug); MDA-MB 231-Rapamycin group (MDA-MB 231 metastatic breast cancer cells treated with $1 \mathrm{ug} / \mathrm{ml}$ Rapamycin) and MCF7-Rapamycin group (MCF-7 non-metastatic breast cancer cells treated with $1 \mathrm{ug} / \mathrm{ml}$ Rapamycin) evaluated the effect of 24-hour Rapamycin treatment.

\section{Immunohistochemical evaluation}

For the indirect immunohistochemical method cells were fixed in $4 \%$ paraformaldehyde in phosphate buffered saline solution (PBS) at $4{ }^{\circ} \mathrm{C}$ for $30 \mathrm{~min}$ and endogenous peroxidase activity was quenched by incubation with $3 \%$ hydrogen peroxide $\left(\mathrm{H}_{2} \mathrm{O}_{2}\right.$, K31355100, Merck, Darmstadt, Germany) for $10 \mathrm{~min}$ at room temperature. After washing with PBS cells were permeabilized with $0.1 \%$ TritonX-100 (A4975, AppliChem, Darmstadt, Germany) in PBS at $4{ }^{\circ} \mathrm{C}$ for $15 \mathrm{~min}$, and then cells were incubated with blocking serum (ready to use according to manufacturer's instruction, 85-9043, Invitrogen, Camarillo, CA, USA). Then anti-mTORC1 (Sc-27744, Santa Cruz Biotechnology, Heidelberg, Germany), anti-mTORC2 (Sc-130865, Santa Cruz Biotechnology, Heidelberg, Germany), anti-pAKT1/2/3 (Sc-135651, Santa Cruz Biotechnology, Heidelberg, Germany), anti-PI3K (Sc-1637, Santa Cruz Biotechnology, Heidelberg, Germany), anti-ERK (Sc94, Santa Cruz Biotechnology, Heidelberg, Germany), anti-IGF1 (Sc-9013, Santa Cruz Biotechnology, Heidelberg, Germany), anticaspase3 (Bs-0081R, Bios, MA, USA), anti-caspase8 (Bs-0052R, Bios, MA, USA), anti-caspase9 (Bs-0049R, Bios, MA,USA) and anti-APAF (Sc-65890, Santa Cruz Biotechnology, Heidelberg, Germany) all primary antibodies were diluted $1: 100$ in blocking serum for immunohistochemistry and incubated at $4{ }^{\circ} \mathrm{C}$ overnight. After washing with PBS, the secondary antibodies, biotinylated goat IgG anti rabbit/mouse IgG and peroxidase-conjugated streptavidin were incubated for $30 \mathrm{~min}$ for each step. Diaminobenzidine was applied to the cells as chromogen and for the background staining, Mayer's hematoxylin was used. Cells were covered with mounting medium, then viewed under light microscope (Olympus BX40). The distribution of immunohistochemical intensities of primary antibodies were scored as mild $(+)$, moderate $(++)$, strong $(+++)$ and very strong $(++++)$. After counting the percentage of positive staining cells, statistical significance was determined by assessment of differences using the ANOVA test. Significance was defined as $\mathrm{p}<0.05$.

\section{Tunel evaluation}

For the TUNEL method (In situ cell death detection kit, 11 684817910 , Roche), cells were fixed in $4 \%$ paraformaldehyde in phosphate buffered saline solution (PBS) at $4{ }^{\circ} \mathrm{C}$ for $30 \mathrm{~min}$ and endogenous peroxidase activity was quenched by incubation with $3 \%$ hydrogen peroxide $\left(\mathrm{H}_{2} \mathrm{O}_{2}, \mathrm{~K} 31355100\right.$, Merck, Darmstadt, Germany) for $10 \mathrm{~min}$ at room temperature. After washing with PBS cells were permeabilized with $0.1 \%$ TritonX-100 (A4975, AppliChem, Darmstadt, Germany) in PBS at $4{ }^{\circ} \mathrm{C}$ for $15 \mathrm{~min}$, TUNEL reaction mixture was applied to the cells for $60 \mathrm{~min}$ at 37 ${ }^{\circ} \mathrm{C}$ in a humidified atmosphere in the dark. Then converter-POD 

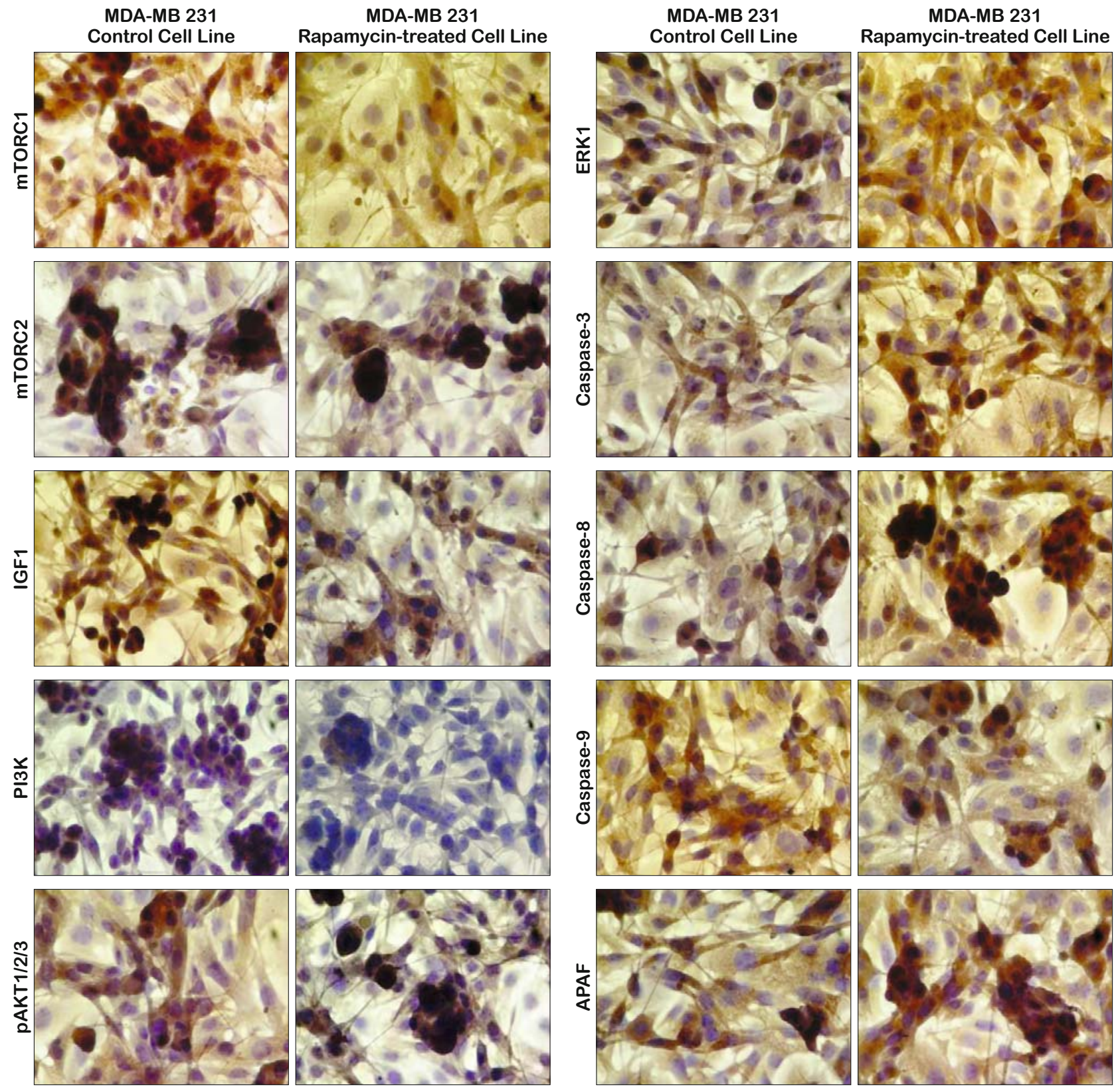

Fig. 1. Distribution of mTORC1, mTORC2, pAKT, PI3K, ERK, IGF, Caspase3, 8, 9 and APAF immunoreactivities of samples from non-treated control and Rapamycin-treated groups in MDA-MB 231 cell line. Original magnification: 400X.

solution was applied for $10 \mathrm{~min}$ at $37^{\circ} \mathrm{C}$. Diaminobenzidine was applied to the cells as chromogen and for the background staining, Mayer's hematoxylin was used. Cells were covered with mounting medium, then viewed under light microscope (Olympus BX40).

\section{Results}

According to the immunohistochemical evaluation, mTORC1, mTORC2 and IGF immunoreactivities were observed to be very strong, pAKT, PI3K and ERK immunoreactivities were strong in the control groups (metastatic MDA-MB 231 and non-metastatic
MCF-7 cells without any treatment). In the control groups of both cell lines, the mTOR pathway molecules were determined to have similar immunoreactivities. Rapamycin treated MDA-MB 231 and MCF-7 cells showed high mTORC2, pAKT and ERK immunoreactivities while mTORC1 immunoreactivity statistically decreased in rapamycin treated groups compared with the control groups $(\mathrm{p}<$ $0.001)$. pAKT $(\mathrm{p}<0.01)$ and ERK $(\mathrm{p}<0.05)$ immunoreactivities were significantly increased in rapamycin treatment groups compared to control groups. mTORC 2 immunoreactivity was similarly strong in both the control and the rapamycin treated groups. PI3K and IGF immunoreactivities were observed to be significantly decrease 



Fig. 2. Distribution of mTORC1, mTORC2, pAKT, PI3K, ERK, IGF, Caspase3, 8, 9 and APAF immunoreactivities of samples from non-treated control and Rapamycin-treated groups in MCF-7 cell line. Original magnification: 400X.

in rapamycin traeted MDA-MB 231 cells $(\mathrm{p}<0.05)$ while there was no difference in the rapamycin treated MCF-7 cells when compared to control groups. When examining the results, immunoreactivities were evaluated separately for each cell line (Figure 1 for MDAMB 231 cell line, Figure 2 for MCF-7 cell line) (Tabs 1 and 2).

Caspase 3, 8, 9 and APAF immunoreactivities were moderate in the MDA-MB 231 control cells while caspase 3, 8 and APAF immunoreactivities were mild and caspase 9 immunoreactivity was moderate in MCF 7 control cells. In rapamycin treated groups caspase 3, 8, 9 and APAF immunoreactivities were observed as strong to very strong (Figs 1 and 2). When apoptotic markers were evaluated statistically, immunoreactivities of rapamycin treatment groups were found to be significantly increased $(p<0.001)$. (Figs 1 and 2). In concordance with the immunohistochemistry results there were much more TUNEL positive cells in rapamycin treated MDA-MB 231 and MCF-7 cell lines when compared with the nontreated MDA-MB 231 and MCF-7 cell lines (p < 0.05) (Fig. 3).

\section{Discussion and conclusion}

In this study we showed the activation of PI3K/AKT/mTOR and related molecular signal pathways in MCF-7 and MDA-MB 
Tab. 1. Immunostaining intensities of mTORC1, mTORC2, IGF1, PI3K, pAKT1/2/3, ERK1 and Caspase-3, Caspase-8, Caspase-9 and APAF in MDA-MB 231 control and rapamycin-treated cell lines.

\begin{tabular}{lcc}
\hline Antibody & $\begin{array}{c}\text { MDA-MB 231 } \\
\text { Control Cell Line }\end{array}$ & $\begin{array}{c}\text { MDA-MB 231 } \\
\text { Rapamycin-treated Cell Line }\end{array}$ \\
\hline mTORC1 & +++ & ++ \\
\hline mTORC2 & ++++ & ++++ \\
\hline IGF1 & ++++ & +++ \\
\hline PI3K & +++ & ++ \\
\hline pAKT1/2/3 & +++ & ++++ \\
\hline ERK & +++ & ++++ \\
\hline Caspase-3 & ++ & +++ \\
\hline Caspase-8 & ++ & ++++ \\
\hline Caspase-9 & ++ & ++++ \\
\hline APAF & ++ & +++
\end{tabular}

Tab. 2. Immunostaining intensities of mTORC1, mTORC2, IGF1, PI3K, pAKT1/2/3, ERK1 and Caspase-3, Caspase-8, Caspase-9 and APAF in MCF-7 control and rapamycin-treated cell lines.

\begin{tabular}{lcc}
\hline Antibody & $\begin{array}{c}\text { MCF-7 } \\
\text { Control Cell Line }\end{array}$ & $\begin{array}{c}\text { MCF-7 } \\
\text { Rapamycin-treated Cell Line }\end{array}$ \\
\hline mTORC1 & +++ & ++ \\
\hline mTORC2 & ++++ & $+++/+++$ \\
\hline IGF1 & ++++ & ++++ \\
\hline PI3K & +++ & +++ \\
\hline pAKT1/2/3 & +++ & ++++ \\
\hline ERK & +++ & ++++ \\
\hline Caspase-3 & ++ & ++++ \\
\hline Caspase-8 & ++ & +++ \\
\hline Caspase-9 & ++ & ++++ \\
\hline APAF & ++ & ++++ \\
\hline
\end{tabular}

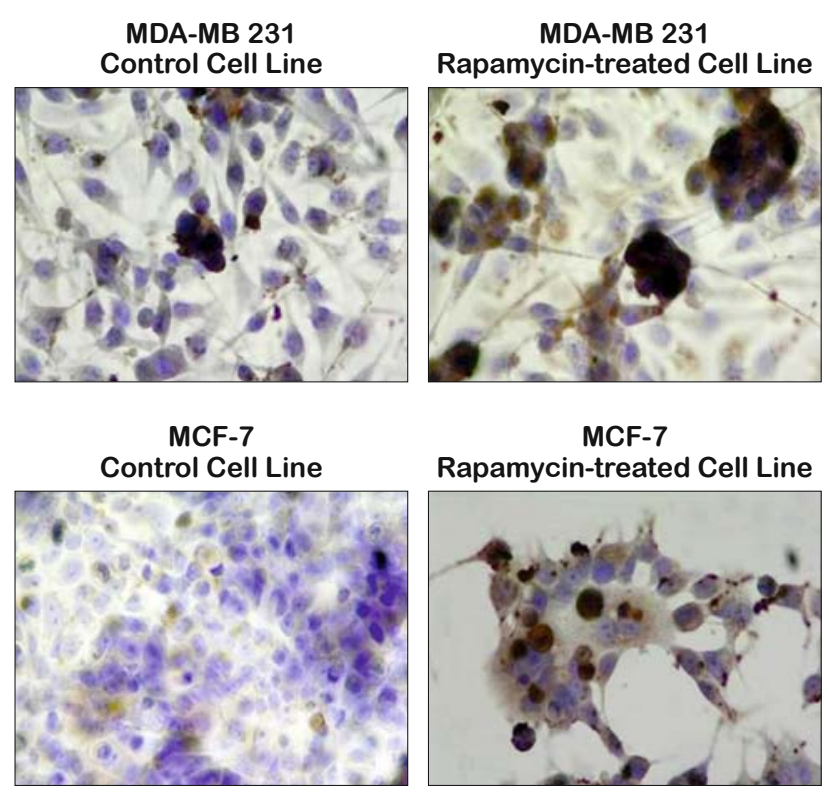

Fig. 3. TUNEL positive cells of samples from non-treated control and Rapamycin-treated groups in MDA-MB 231 and MCF-7 cell lines. Original magnification: $400 \mathrm{X}$.
231 human breast cancer cell lines using indirect immunohistochemistry and TUNEL methods. It was observed that mTORC1 was inhibited by Rapamycin, while there was no change in mTORC2 immunoreactivity in both groups.

$\mathrm{PI} 3 \mathrm{~K} / \mathrm{AKT} / \mathrm{mTOR}$ and related Raf/MEK/ERK pathways are involved in the pathology of breast cancer. One of the major molecules in these pathways is mTOR. mTOR signals are often regulated in malignant tumors, including breast cancer, which emphasize the potential importance of mTOR-targeted therapy in cancer pathogenesis (35-38).

According to the immunohistochemical evaluation, mTORC1, mTORC2 and IGF immunoreactivities were observed to be very strong, pAKT, PI3K and ERK immunoreactivities were strong in the control group. Compared with the control group, as expected, mTORC1 immunoreactivity decreased in both rapamycin treated MDA-MB 231 and MCF-7 breast cancer cell lines. Also pAKT and ERK immunoreactivities increased in all rapamycin treated groups compared with the control. IGF1 and mTORC2 did not differ significantly. Since rapamycin is essentially an inhibitor of mTORC1, it was considered usual to have no changes in mTORC2. Increased pAKT and ERK immunoreactivities are expected because the increase in pAKT and ERK suppresses the transcription of mTORC1 $(39,40)$. Suppression of mTORC1 via pAKT or ERK was evaluated as a promising treatment of rapamycin in breast cancer.

The results of this study show that rapamycin has anti-cancer activity on metastatic MDA-MB 231 and non-metastatic MCF-7 breast cancer cells and this effect is mediated via the mTORC1 pathway, and rapamycin increases apoptosis in breast cancer cells.

mTOR is a downstream effector of PI3K and AKT. mTORC1 is the target of rapamycin and rapamycin analogues, such as everolimus, and leads to cell anabolic growth by promoting mRNA translocation and protein synthesis $(41,42)$ and also has roles in glucose metabolism and lipid synthesis. Its downstream substrate S6 kinase 1 can phosphorylate the activation function domain 1 of the ER, which is responsible for ligand-independent receptor activation $(43,44)$. Many mTORC1 functions are highly sensitive to rapamycin, whereas how FKBP12-rapamycin inhibits the activity of binding to mTORC1 is not fully known. It has been speculated that Rapamycin jeopardizes the structural integrity of mTORC1 and allostically reduces the specific activity of the kinase domain $(23,45,46)$. Mutations and amplifications in genes encoding growth factors such as IGF1R (insulin-like growth factor 1 receptor) (47, 48), PIK3CA (49, 50), PDK1 (51), HER2 (52, 53) RAC-alpha serine/threonine protein kinase (AKT1) $(54,55)$ and fibroblast growth factor receptor 1 (FGFR1) (56) and loss of function or reduced expression of the genes encoding PTEN, 47 INPP4B $(57,58)$ and LKB1 (59) in breast cancer indicate the mTOR pathway.

Rapalog therapy may activate mTOR negative feedback on alternative pathways such as signaling pathways such as PI3K/ AKT and MAPK/ERK (60-62). This observation highlights the need for alternative combinational therapeutic approaches for breast cancer treatment. 
MAPK and PI3K/AKT pathways stimulate cell proliferation and increase cell survival through activation of transcription factors and cyclin D1 upregulation (63). PI3K is the main regulator of AKT activation and myogenesis (64). Combination of the rapamycin analogue everolimus and an ATP-competitive mTOR inhibitor BEZ235 showed synthetic lethality in several mTORaddicted triple-negative breast cancer (TNBC) cell lines (65). Given the fundamental role of mTOR pathway signaling in the maintenance of ER positive breast cancer and its emerging role in resistance to endocrine therapy, strategic inhibition of pathway signaling must be considered in the treatment of ER+ breast cancer. This rationalizes the use of endocrine therapy and mTOR pathway inhibition in combination (49).

Abrogation of the negative feedback loop by mTORC1 inhibitors has only been demonstrated to influence PI3K/AKT signaling, whereas the impact of mTORC1 inhibition in other prosurvival pathways has not been addressed (60). This negative feedback loop has been directly related to the indolence of some types of cancers, suggesting that tumors with aberrant mTORC1 activation may in turn display reduced PI3K/AKT activity. Some researches have shown that the activation of mTORC1 regulates the expression of PDGFRs and that rapamycin treatment restores PDGFR levels and therefore PI3K signaling (66).

It was seen that Caspase 3, 8, 9 and APAF immunoreactivities were increased in rapamycin treated groups compared with the control groups. It was thought that both intrinsic and extrinsic pathways of caspase activation were involved in rapamycin induced apoptosis. In conclusion, these pathways may play an important role in cancer pathogenesis and new drug development for PI3K and mTORC2 inhibition is required.

In our study, activation of molecular pathways associated with $\mathrm{PI} 3 \mathrm{~K} / \mathrm{AKT} / \mathrm{mTOR}$ and ERK in metastatic MDA-MB 231 and nonmetastatic MCF-7 human breast cancer cell lines was evaluated and it was observed that these pathways could play a key role in the cancer survival.

It was considered that mTORC1 inhibition was achieved with Rapamycin administration for 24 hours and apoptotic cells were increased in cancer groups and would be suitable for use in treatment. It was also thought that increased immunoreactivity of PI3K, AKT and ERK may be developed by negative feed back mechanisms and it may be important to develop drug protocols for inhibition of these pathways.

\section{References}

1. Stewart B, Wild C. World Cancer Report 2014. Int Agency Res Cancer 2014; 22 (1): 3-4.

2. Bray F, Ferlay J, Soerjomataram I, Siegel RL, Torre LA, Jemal A. Global cancer statistics 2018: GLOBOCAN estimates of incidence and mortality worldwide for 36 cancers in 185 countries. CA Cancer J Clin [Internet] 2018; 68 (6): 394-424. http://www.ncbi.nlm.nih.gov/ pubmed/30207593

3. Blamey RW, Hornmark-Stenstam B, Ball G, Blichert-Toft M, Cataliotti L, Fourquet A et al. ONCOPOOL - A European database for 16,944 cases of breast cancer. Eur J Cancer 2010; 46 (1): 56-71.
4. De Jong PC, Blijham GH. New aromatase inhibitors for the treatment of advanced breast cancer in postmenopausal women. Neth J Med 1999; 55 (2): 50-58.

5. Swain SM, Baselga J, Kim SB, Ro J, Semiglazov V, Campone M et al. Pertuzumab, Trastuzumab, and Docetaxel in HER2-Positive Metastatic Breast Cancer. N Engl J Med [Internet] 2015; 372 (8): 724-734. Available from: http://www.nejm.org/doi/10.1056/NEJMoa1413513

6. Haffer CL, Weinberg RA. A perspective on cancer cell metastasis. Science 2011; 331: 1559-1564.

7. Wu Q, Li J, Zhu S, Wu J, Chen C, Liu Q et al. Breast cancer subtypes predict the preferential site of distant metastases: a SEER based study. Oncotarget 2017; 8 (17).

8. Perou CM, Sørile T, Eisen MB, Van De Rijn M, Jeffrey SS, Ress CA et al. Molecular portraits of human breast tumours. Nature 2000; 406 (6797): 747-572.

9. Grant S. Cotargeting survival signaling pathways in cancer. J Clin Invest 2008; 118: 3003-3006.

10. Saini KS, Loi S, de Azambuja E, Metzger-Filho O, Saini ML, Ignatiadis $M$ et al. Targeting the PI3K/AKT/mTOR and Raf/MEK/ERK pathways in the treatment of breast cancer. Cancer Treatment Rev 2013; 39: 935-946.

11. Guertin DA, Sabatini DM. Defining the Role of mTOR in Cancer. Cancer Cell 2007.

12. Laplante M, Sabatini DM. mTOR signaling at a glance. J Cell Sci 2009;

13. Hay N, Sonenberg N. Upstream and downstream of mTOR. Genes and Development 2004.

14. Dey N, De P, Leyland-Jones B. PI3K-AKT-mTOR inhibitors in breast cancers: From tumor cell signaling to clinical trials. Pharm Ther 2017; 175: 91-106.

15. Rahman A, Haugh JM. Kinetic modeling and analysis of the Akt/ mechanistic target of rapamycin complex 1 (mTORC1) signaling axis reveals cooperative, feedforward regulation. J Biol Chem 2017; 292 (7): 2866-2872.

16. Treins C, Warne PH, Magnuson MA, Pende M, Downward J. Rictor is a novel target of p70 S6 kinase-1. Oncogene 2010.

17. Manning BD. Balancing Akt with S6K. J Cell Biol 2004.

18. Laplante M, Sabatini DM. MTOR signaling in growth control and disease. Cell 2012; 149: 274-293.

19. Huber TB, Walz G, Kuehn EW. MTOR and rapamycin in the kidney: Signaling and therapeutic implications beyond immunosuppression. Kidney Internat 2011; 79: 502-511.

20. Schenone S, Brullo C, Musumeci F, Radi M, Botta M. ATP-Competitive Inhibitors of mTOR: An Update. Curr Med Chem 2011.

21. Wullschleger S, Loewith R, Hall MN. TOR signaling in growth and metabolism. Cell 2006.

22. Zhang X, Reed EF. Effect of antibodies on endothelium: Minireview. Amer J Transplant 2009.

23. Sarbassov DD, Guertin DA, Ali SM, Sabatini DM. Phosphorylation and regulation of Akt/PKB by the rictor-mTOR complex. Science 2005; 307 (5712): 1098-1101.

24. Huang J, Manning BD. A complex interplay between Akt, TSC2 and the two mTOR complexes. Biochem Soc Transactions 2009. 
25. Lewis TS, Shapiro PS, Ahn NG. Signal Transduction through MAP Kinase Cascades. Adv Cancer Res 1998; 74: 49-139.

26. Pazarbaşı A, Kasap M, Kasap H. Kanser Yolakları [Internet]. Vol 20, Arşiv Kaynak Tarama Dergisi 2011. Available from: http://dergipark. ulakbim.gov.tr/arsiv/article/view/5000072612

27. Boulton TG, Yancopoulos GD, Gregory JS, Slaughter C, Moomaw C, Hsu J et al. An insulin-stimulated protein kinase similar to yeast kinases involved in cell cycle control. Science (80) 1990.

28. Boulton TG, Nye SH, Robbins DJ, Ip NY, Radzlejewska E, Morgenbesser SD et al. ERKs: A family of protein-serine/threonine kinases that are activated and tyrosine phosphorylated in response to insulin and NGF. Cell 1991.

29. Brown EJ, Albers MW, Bum Shin T, Ichikawa K, Keith CT, Lane WS et al. A mammalian protein targeted by G1-arresting rapamycin-receptor complex. Nature 1994; 369 (6483): 756-758.

30. Sabatini DM, Erdjument-Bromage H, Lui M, Tempst P, Snyder SH. RAFT1: A mammalian protein that binds to FKBP12 in a rapamycin-dependent fashion and is homologous to yeast TORs. Cell 1994; 78 (1): 35-43.

31. Sabers CJ, Martin MM, Brunn GJ, Williams JM, Dumont FJ, Wiederrecht $\mathbf{G}$ et al. Isolation of a protein target of the FKBP12-rapamycin complex in mammalian cells. J Biol Chem 1995; 270 (2): 815-822.

32. Mazzoni SM, Walker NM, Chan KM, Stuckey L, Chang A, Lin $\mathbf{J}$ et al. Mechanistic Target of Rapamycin Complex 1 (mTORC1) and mTORC2 as Key Signaling Intermediates in Mesenchymal Cell Activation. J Biol Chem 2016; 291 (12): 6262-6271.

33. Ekshyyan O, Khandelwal AR, Rong X, Moore-Medlin T, Ma X, Alexander JS et al. Rapamycin targets interleukin 6 (IL-6) expression and suppresses endothelial cell invasion stimulated by tumor cells. Am J Transl Res 2016.

34. Price KAR, Cohen EEW. Mechanisms of and therapeutic approaches for overcoming resistance to epidermal growth factor receptor (EGFR)-targeted therapy in squamous cell carcinoma of the head and neck (SCCHN). Oral Oncol 2015.

35. Bahrami A, Khazaei M, Shahidsales S, Hassanian SM, Hasanzadeh M, Maftouh M et al. The Therapeutic Potential of PI3K/Akt/mTOR Inhibitors in Breast Cancer: Rational and Progress. J Cell Biochem 2018.

36. Saxton RA, Sabatini DM. mTOR Signaling in Growth, Metabolism, and Disease. Cell 2017.

37. Conciatori F, Ciuffreda L, Bazzichetto C, Falcone I, Pilotto S, Bria $\mathbf{E}$ et al. MTOR cross-talk in cancer and potential for combination therapy. Cancers 2018.

38. Costa RLB, Han HS, Gradishar WJ. Targeting the PI3K/AKT/mTOR pathway in triple-negative breast cancer: a review. Breast Cancer Research and Treatment 2018.

39. Jóźwiak P, Forma E, Bryś M, Krześlak A. O-GlcNAcylation and metabolic reprograming in cancer. Frontiers in Endocrinology 2014.

40. Mendoza MC, Er EE, Blenis J. The Ras-ERK and PI3K-mTOR pathways: Cross-talk and compensation. Trends in Biochemical Sciences 2011.

41. Fogel AL, Hill S, Teng JMC. Advances in the therapeutic use of mammalian target of rapamycin (mTOR) inhibitors in dermatology. J Amer Acad Dermatol 2015; 72: 879-889.

42. Chan JYL, Wang KH, Fang CL, Chen WY. Fibrous papule of the face, similar to tuberous sclerosis complex-associated angiofibroma, shows activation of the mammalian target of rapamycin pathway: Evidence for a novel therapeutic strategy? PLoS One 2014; 9 (2).
43. Zoncu R, Efeyan A, Sabatini DM. MTOR: From growth signal integration to cancer, diabetes and ageing. Nature Rev Mol Cell Biol 2011; 12: $21-35$.

44. Yamnik RL, Digilova A, Davis DC, Brodt ZN, Murphy CJ, Holz MK. S6 Kinase 1 Regulates Estrogen Receptor $\alpha$ in Control of Breast Cancer Cell Proliferation. J Biol Chem [Internet] 2009 Mar 6; 284 (10): 6361-9. Available from: http://www.jbc.org/lookup/doi/10.1074/jbc.M807532200

45. Yip CK, Murata K, Walz T, Sabatini DM, Kang SA. Structure of the Human mTOR Complex I and Its Implications for Rapamycin Inhibition. Mol Cell 2010; 38 (5): 768-774.

46. Madala SK, Thomas G, Edukulla R, Davidson C, Schmidt S, Schehr A et al. p70 ribosomal S6 kinase regulates subpleural fibrosis following transforming growth factor- $\alpha$ expression in the lung. Am J Physiol Cell Mol Physiol 2015; 310 (2): L175-186.

47. Fu P, Ibusuki M, Yamamoto Y, Hayashi M, Murakami K, Zheng $\mathbf{S}$ et al. Insulin-like growth factor-1 receptor gene expression is associated with survival in breast cancer: A comprehensive analysis of gene copy number, mRNA and protein expression. Breast Cancer Res Treat 2011; 130 (1): 307-317.

48. Davison Z, de Blacquière GE, Westley BR, May FEB. Insulin-like Growth Factor-Dependent Proliferation and Survival of Triple-Negative Breast Cancer Cells: Implications for Therapy. Neoplasia 2015; 13 (6): 504-515.

49. Ciruelos Gil EM. Targeting the PI $3 \mathrm{~K} / \mathrm{AKT} / \mathrm{mTOR}$ pathway in estrogen receptor-positive breast cancer. Cancer Treat Rev 2014; 40: 862-871.

50. Gonzalez-Angulo AM, Ferrer-Lozano J, Stemke-Hale K, Sahin A, Liu S, Barrera JA et al. PI3K Pathway Mutations and PTEN Levels in Primary and Metastatic Breast Cancer. Mol Cancer Ther 2011; 10 (6): 1093-101.

51. Surviladze Z, Sterk RT, DeHaro SA, Ozbun MA. Cellular Entry of Human Papillomavirus Type 16 Involves Activation of the Phosphatidylinositol 3-Kinase/Akt/mTOR Pathway and Inhibition of Autophagy. J Virol 2013; 87 (5): 2508-2517.

52. Aurilio G, Disalvatore D, Pruneri G, Bagnardi V, Viale G, Curigliano $\mathbf{G}$ et al. A meta-analysis of oestrogen receptor, progesterone receptor and human epidermal growth factor receptor 2 discordance between primary breast cancer and metastases. Eur J Cancer 2014; 50 (2): 277-289.

53. Van de Ven S, Smit VTHBM, Dekker TJA, Nortier JWR, Kroep JR. Discordances in ER, PR and HER2 receptors after neoadjuvant chemotherapy in breast cancer. Cancer Treat Rev 2011; 37: 422-430.

54. Loi S, Michiels S, Baselga J, Bartlett JMS, Singhal SK, Sabine VS et al. PIK3CA Genotype and a PIK3CA Mutation-Related Gene Signature and Response to Everolimus and Letrozole in Estrogen Receptor Positive Breast Cancer. PLoS One 2013; 8 (1).

55. Dave B, Mittal V, Tan NM, Chang JC. Epithelial-mesenchymal transition, cancer stem cells and treatment resistance. Breast Cancer Res $2011 ; 14$

56. Tomiguchi M, Yamamoto Y, Yamamoto-Ibusuki M, Goto-Yamaguchi L, Fujiki Y, Fujiwara S et al. Fibroblast growth factor receptor-1 protein expression is associated with prognosis in estrogen receptor-positive/human epidermal growth factor receptor-2-negative primary breast cancer. Cancer Sci 2016; 107 (4): 491-498.

57. Juvekar A, Burga LN, Hu H, Lunsford EP, Ibrahim YH, Balmañà $\mathbf{J}$ et al. Combining a PI3K inhibitor with a PARP inhibitor provides an effective therapy for BRCA1-related breast cancer. Cancer Discov 2012; 2 (11): 1048-1063. 
58. Fedele CG, Ooms LM, Ho M, Vieusseux J, O'Toole SA, Millar EK et al. Inositol polyphosphate 4-phosphatase II regulates PI3K/Akt signaling and is lost in human basal-like breast cancers. Proc Natl Acad Sci 2010; 107 (51): 22231-22236.

59. Chen IC, Chang YC, Lu YS, Chung KP, Huang CS, Lu TP et al. Clinical Relevance of Liver Kinase B1 (LKB1) Protein and Gene Expression in Breast Cancer. Sci Rep [Internet] 2016 Feb 15; 6 (1): 21374 . Available from: http://www.nature.com/articles/srep21374

60. Carracedo A, Ma L, Teruya-Feldstein J, Rojo F, Salmena L, Alimonti A et al. Inhibition of mTORC1 leads to MAPK pathway activation through a PI3K-dependent feedback loop in human cancer. J Clin Invest 2008; 118 (9): 3065-74.

61. Yu Y, Yoon SO, Poulogiannis G, Yang Q, Ma XM, Villén J et al. Phosphoproteomic analysis identifies Grb10 as an mTORC1 substrate that negatively regulates insulin signaling. Science (80) 2011.

62. Faes S, Demartines N, Dormond O. Resistance to mTORC1 Inhibitors in Cancer Therapy: From Kinase Mutations to Intratumoral Heterogeneity of Kinase Activity. Oxidative Med Cell Longevity 2017.
63. Lee RJ, Albanese C, Fu M, D'Amico M, Lin B, Watanabe G et al. Cyclin D1 Is Required for Transformation by Activated Neu and Is Induced through an E2F-Dependent Signaling Pathway. Mol Cell Biol 2000.

64. Matheny RW, Lynch CM, Leandry LA. Enhanced Akt phosphorylation and myogenic differentiation in PI3K p110 3 -deficient myoblasts is mediated by PI3K p $110 \alpha$ and mTORC2. Growth Factors 2012; 30 (6): 367-384.

65. Ito Y, Masuda N, Iwata H, Mukai H, Horiguchi J, Tokuda $Y$ et al. Everolimus plus exemestane in postmenopausal patients with estrogenreceptor-positive advanced breast cancer - Japanese subgroup analysis of BOLERO-2. Gan To Kagaku Ryoho [Internet] 2015; 42 (1): 67-75. Available from: https://www.cochranelibrary.com/central/doi/10.1002/central/ $\mathrm{CN}-01111036 /$ full

66. Zhang H, Bajraszewski N, Wu E, Wang H, Moseman AP, Dabora SL et al. PDGFRs are critical for PI3K/Akt activation and negatively regulated by mTOR. J Clin Invest 2007; 117 (3): 730-738.

Received December 14, 2019. Accepted January 19, 2020. 